\title{
About power quality monitoring in residential grids
}

\author{
M. Buzdugan, H. Balan \\ Technical University of Cluj-Napoca, \\ 28, Memorandumului str., Cluj-Napoca (Romania), \\ Phone number: +40 744560 833, Fax number: +40 264410 179, \\ e-mail: mircea.buzdugan@insta.utcluj.ro, \\ horia.balan@eps.utcluj.ro
}

\begin{abstract}
The paper presents some voltage power quality issues in a low voltage residential area. In the introductory section, a few specific problems related to the monitoring process are addressed. The following section is devoted to the power quality survey intended for diagnosis. A portable hand-held, eight channels, power quality meter/monitor. It was a reactive mode of power quality survey, determined by the misoperation of the home automation in a residence, which was the first step to a solution of mitigating the power quality issues.
\end{abstract}

\section{Key words}

PQ monitoring, PQ events, PQ meter, PQ survey

\section{Introduction}

According to the standard (IEEE Std. 1159-1995 R2001) IEEE Recommended Practice for Monitoring Electric Power Quality and the related ones), the term power quality refers to a wide variety of electromagnetic phenomena that characterize the voltage and current at a given time and at a given location on the power system [1].

In recent years, the increasing application of electronic equipment that can cause electromagnetic disturbances, or that can be sensitive to these phenomena, has heightened the interest in power quality.

Considering the electromagnetic compatibility approach to describing power quality phenomena, the electromagnetic disturbances classified by the IEC are:

- Conducted low frequency phenomena (harmonics, interharmonics, voltage fluctuations and imbalance, power frequency variations, induced low frequency voltages and DC in ac networks).

- Radiated low frequency phenomena (magnetic fields, electric fields)

- Conducted high frequency phenomena (induced continuous wave voltages or currents, unidirectional transients, oscillatory transients)

- Radiated high frequency phenomena (magnetic fields, electric fields, electromagnetic fields, continuous waves, transients).
- Electrostatic discharge phenomena

For steady-state phenomena, the following attributes can be used: amplitude, frequency, spectrum, modulation, source impedance, notch depth, notch area. For nonsteady state phenomena, other attributes may be required: rate of rise, amplitude, duration, spectrum, frequency, rate of occurrence, energy potential and source impedance.

In conformity with the standard IEC 61000-4-30 Edition 3.02015 - 02 - Electromagnetic compatibility (EMC) Part 4-30: Testing and measurement techniques - Power quality measurement methods, power quality monitoring is carried out for one of three reasons [2]:

a) Troubleshooting: To diagnose incompatibilities between the electric power source and existing equipment connected within an installation.

b) PQ evaluation: To evaluate the electrical environment at a particular location to refine modeling techniques or to develop a power quality baseline.

c) Planning the connection of new equipment: To predict future performance of equipment or power quality mitigating devices that are planned to be connected within an installation. In any event, the most important task in any monitoring project is to define clearly the objectives of monitoring.

The objectives of monitoring for a particular project will determine the choice of monitoring equipment, the method of collecting data, the triggering thresholds needed, the data analysis technique to employ, and the overall level of effort required of the project. The objective may be as simple as verifying steady-state voltage regulation at a service entrance, or may be as complex as analyzing the harmonic current flows within a distribution network. The resulting data need only meet the objectives of the monitoring task in order for the monitoring to be successful.

There are several important reasons to monitor power quality. The primary reason underpinning all others is economic, particularly if critical process loads are being adversely affected by electromagnetic phenomena. 
Effects on equipment and process operations can include misoperation, damage, process disruption, and other such anomalies. Such disruptions are costly since a profit-based operation is interrupted unexpectedly and must be restored to continue production. In addition, equipment damage and subsequent repair cost both money and time.

The initial location to install a power quality monitor will be dependent upon the objective of the survey. If the monitoring objective is to diagnose an equipment performance problem then the monitor should be placed as close to the load as possible. This applies to performance problems with both sensitive electronic loads such as computers and adjustable speed drives, and electrical distribution equipment such as circuit breakers and capacitors. After the voltage fluctuations are detected, the monitor may be moved upstream on the circuit to determine the source of the disturbance.

If the monitoring objective is to investigate the overall quality of a facility then the monitor should be placed on the secondary of the main service entrance transformer. The monitor will record the quality of power supplied to the facility as well as the effect of major loads within the facility. The electrical retail point of sale (POS) and/or the point of common coupling (PCC) are the most common locations for monitoring. In IEEE STD 519-2014 (Recommended Practice and Requirements for Harmonic Control in Electrical Power Systems) [3], the point of common coupling is redefined as a point on a public power supply system, electrically nearest to a particular load, at which other loads are, or could be, connected. The PCC is a point located upstream of the considered installation. For service to industrial users (i.e., manufacturing plants) via a dedicated service transformer, the PCC is at the $\mathrm{HV}$ side of the transformer. For commercial users supplied through a common service transformer, the PCC is commonly on the LV side of the service transformer."

Monitoring to characterize system performance, which is a proactive approach to power quality monitoring; by understanding the normal power quality performance of a system, a provider can quickly identify problems and can offer information to its customers to help them match their sensitive equipment's characteristics with realistic power quality characteristics.

If the monitoring objective is to diagnose an equipment performance problem, the power quality monitor should be placed as close to the symptomatic load as possible. This is a reactive mode of power quality monitoring, but it frequently identifies the cause of equipment incompatibility, which is the first step to a solution.

Harmonics is the most important issue among all issues related to power quality. All transients cause harmonics. To analyze harmonics in power system, different new standards and definitions have been introduced, the most common being the harmonic distortion factors of voltage (THDV) and current (THDI) waveform.

Harmonics are analyzed in time domain, in frequency domain or both time-frequency domains, respectively [4]:
- Fourier series, that expands continuous, single valued function of time domain in terms of dc component, and series of integer harmonics

- Fourier transform, makes possible to express a time domain function in frequency domain, being very useful in handling continuous signal in frequency domain. However, the transform method suffers from limitation to handle discrete or discontinuous, multivalued and undefined signals which are also frequent in electrical applications. Fourier Transform, which has been used for power quality assessment for a long period. Discrete Fourier was able to overcome these drawbacks, but it is a very time consuming method even when a numerical method is used, especially for a large number of samples. The fast Fourier transform reduces the multiplication process as well as the time of execution. For this reason, among them FFT is now extensively used in spectrum analyzer.

- Wavelet Transform: Fourier transform fails in the analysis the non-stationary signals in both time and frequency domains. Wavelet transform becomes useful in such cases.

The monitoring period is a direct function of the monitoring objective. Usually the monitoring period attempts to capture a complete power period, an interval in which the power usage pattern begins to repeat itself.

Some standards specify minimum measurement periods. In any case, event measurements such as voltage dips and swells generally require longer measurement periods in order to capture enough events to provide meaningful statistics (months). Rarer events such as interruptions may require even longer periods; in contrast, for harmonics and other steady state measurements, meaningful information may be captured in relatively short periods of time.

Baseline power monitoring is a relatively short process. Its purpose is to document the power profile at a specific site or location. Primary information is steady-state and transient extremes. In all cases, the data obtained is a snap shot of the power quality profile. Conversely, hunting for a power problem that exhibits a specific equipment load malfunction can take days to weeks. This type of activity is intended to find the specific power disturbance that creates the problem and document its repeatability.

The standard IEC 61000-4-30, power frequency, magnitude of the supply voltage, flicker, supply voltage dips and swells, voltage interruptions, transient voltages, supply voltage unbalance, voltage harmonics and interharmonics, mains signalling on the supply voltage and rapid voltage changes. It also defines for each parameter measured three classes (A, S and B). For each class, measurement methods and appropriate performance requirements are included.

Class A is used where precise measurements are necessary, for example, for contractual applications that may require resolving disputes, verifying compliance with standards, etc. Any measurements of a parameter 
carried out with two different instruments complying with the requirements of Class $\mathrm{A}$, when measuring the same signals, will produce matching results within the specified uncertainty for that parameter.

Class S is used for statistical applications such as surveys or power quality assessment, possibly with a limited subset of parameters. Although it uses equivalent intervals of measurement as class $\mathrm{A}$, the class $\mathrm{S}$ processing requirements are lower.

Class B is defined in order to avoid making many existing instruments designs obsolete. Class B methods are not recommended for new designs therefore these methods are not presented in the body text, but only in an annex in the third edition of the 61000-4-30 standard.

\section{Measurements and Discussions}

In measuring power quality, one must be able to trigger on events that are not continuous (such as voltage sags) or transients (like that caused by lightning strikes or utility faults). For instance, typical power quality meters/analyzers and analyzers have the following functionalities [5]:

- Data logging - capturing waveforms in real-time for later display

- The ability to trigger on power-quality events such as sags, swells, or transients

- Calculation of power-quality metrics such as total harmonic distortion in real-time

- Spectrum analysis

- Inputs for high-voltage probes and high-current probes

Measurements were performed using a portable, handheld, eight-channel power quality meter/monitor, which can survey, record and display data on four voltage channels and four current channels simultaneously. It can monitor single phase or three phase power configurations. It can do PQ-optimized acquisition of power quality related disturbances and events. It is designed with a statistical package called Quality of Supply (QOS), with monitoring and setup protocols set to determine voltage measurement compliance required for EN50160 monitoring [6].

The firmware can monitor power quality phenomena for troubleshooting and/or compliance purposes. It can record inrush conditions, carry out long-term statistical studies to establish performance baselines, and perform field-based equipment testing and evaluation for commissioning and maintenance. The firmware integrates an intuitive instrument setup procedure to ensure the capture of all relevant data for additional post process analysis, report writing, and data archiving. All functions are operable using a color LCD touch screen technology.

Meter mode functions as a true rms voltmeter and a true rms clamp-on ammeter. Voltage and current measurements, along with other calculated and advanced power parameters, are displayed on the meter mode screens in both textual and graphical format.
Harmonics mode displays the amplitude and phase of each harmonic to the 63rd harmonic in both graphical and textual format.

The phasor screen displays a graph that indicates phase relations between voltage and current based upon the angles at the fundamental frequency, as determined by Fourier analysis. Phasor diagram displays voltage and current phasors for all channels. Functioning as a phase angle meter, the unit can display system imbalance conditions and provides such information in textual form also. The phase angle display can also verify if monitoring connections have been made correctly.

The monitor stores all events that occur when a programmed threshold limit is crossed. An event consists of the pre-trigger cycle(s), trigger cycle(s), and posttrigger cycle(s). Note that in conformity with the standard EN 61000-4-30, aggregation is not applicable for triggered events.

The following subsections will focus mainly on transients that determine on one hand harmonics and on the other hand conducted electromagnetic emissions (see [7]).

In conformity with the standard IEEE Std. 1159-1995 $\mathrm{R} 2001$, the transients are classified in the following categories:

- Oscillatory, representing a sudden, non-power frequency change in the steady state condition of voltage, current or both, that includes both positive and negative polarity values.

- Low Frequency, representing a transient with a primary frequency component less than $5 \mathrm{kHz}$ and a duration from $0.3 \mathrm{~ms}$ to $50 \mathrm{~ms}$.

- Medium Frequency, representing a transient with a primary frequency between 5 and $500 \mathrm{kHz}$ with duration measured in the tens of microseconds.

- High Frequency Oscillatory transients with a primary frequency greater than $500 \mathrm{kHz}$ and a typical duration measured in microseconds.

- Impulsive, representing a sudden, non-power frequency change in the steady state condition of voltage, current or both, that is unidirectional in polarity. Lightning is the most common cause of impulsive transients.

\section{A. Triggered $P Q$ events in a $L V$ transformer substation}

The survey focused on the supply system performance. Consequently, the first measurement point was located on the secondary busbars of the transformer substation $(10 / 0.4 \mathrm{kV}, 100 \mathrm{kVA})$ in $\Delta-\mathrm{Y}$ connection, supplying a residential area. One of the major advantages of the $\Delta-Y$ connection of the power transformers is that it provides harmonic suppression.

Fig. 1 depicts the ITIC curve (issued by the Information Technology Industry Council), which represents a modified version of the CBEMA power acceptability curve for power quality evaluation. The figure reveals six 
points (the green dots) in which the rms voltage of line B is below the tolerance curve, which means that in the survey interval some power quality highly important events occurred.

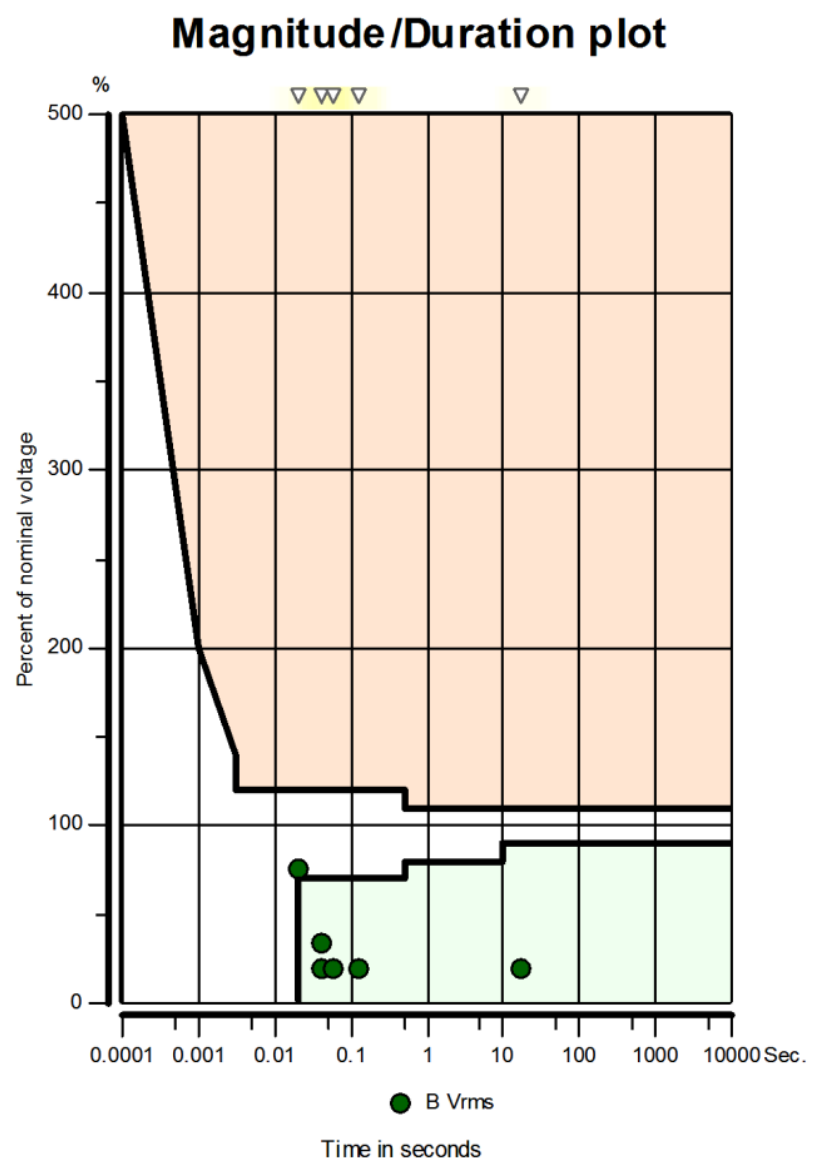
Nominal voltage $(100 \%)=230 \mathrm{~V}$ Variations ABOVE tolerance curve Variations BELOW tolerance curve 6

Fig. 1 The ITIC curve of the survey

\section{Event Details/Waveforms}
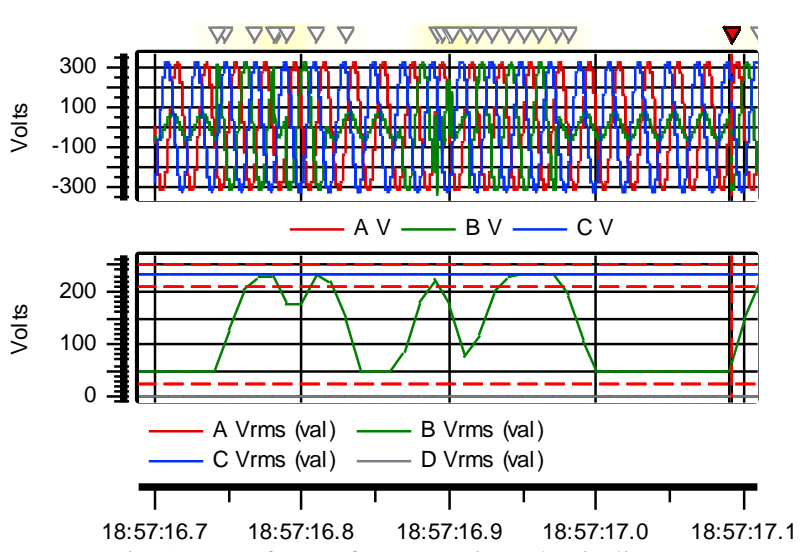

Fig. 2 Waveform of a severe impulse in line B

One of the events, i.e. a severe impulse on line B is depicted in Fig. 2. The impulse is preceded by one instantaneous sag of $46.49 \mathrm{~V}$ and duration of 0.13 seconds, and followed by a series of mild impulse and bipolar transients.

The frequency discrete spectrum of the impulse is also available in the survey, being depicted in Fig. 3. From Fig. 4 which depicts the main features of the event, one can see that the magnitude of the fundamental drops to 200.07 V, associated with a DC component of $24.65 \mathrm{~V}$.

The total harmonic distortion of the voltage THDV value in line $\mathrm{B}$ is $76.85 \mathrm{~V}$ in absolute value, and $38.41 \%$ in relation to the fundamental. Even if the other two lines are "healthy", the THDV between the lines A-B and B-C have also large values around $76 \%$. It is obvious that this high harmonic content will determine conducted electromagnetic interference in the frequency range from $150 \mathrm{kHz}$ to $30 \mathrm{MHz}$.

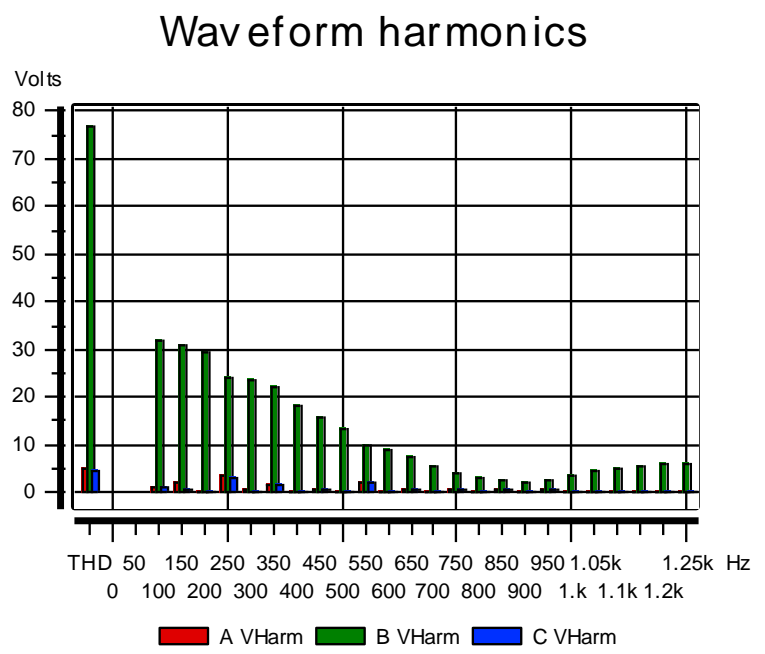

Fig. 3 The discrete frequency spectrum of the event

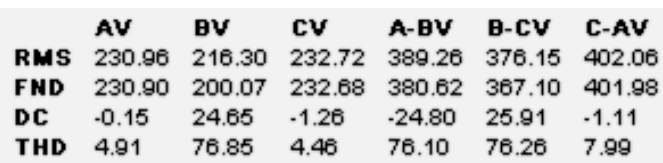

Fig. 4. The detailed features during the event

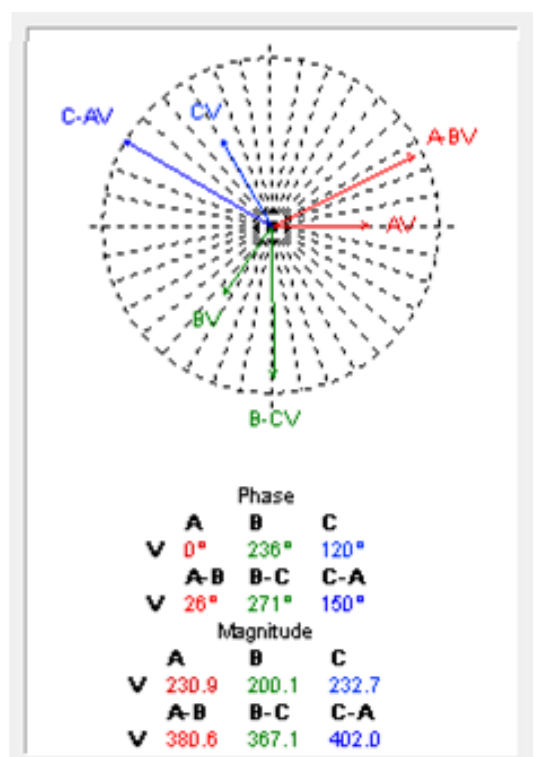

Fig. 5 Voltages imbalance of the fundamental

The voltage imbalance between the three lines is also available both for the fundamental and for each harmonic component. In Fig. 5 is depicted the voltage imbalance of the fundamental. 


\section{B. Triggered events in a residential point of sale}

The following survey is carried out in a single phase residential system measured using channel $\mathrm{A}$ for the line and channel D for the neutral. The survey was determined by the misoperation of some house hold appliances. In a short survey, of more than one day, 956 triggered events were stored in the memory of the measuring equipment. The time plot of the survey depicts a lot of voltage sags, transients and severe impulses (Fig. 6).

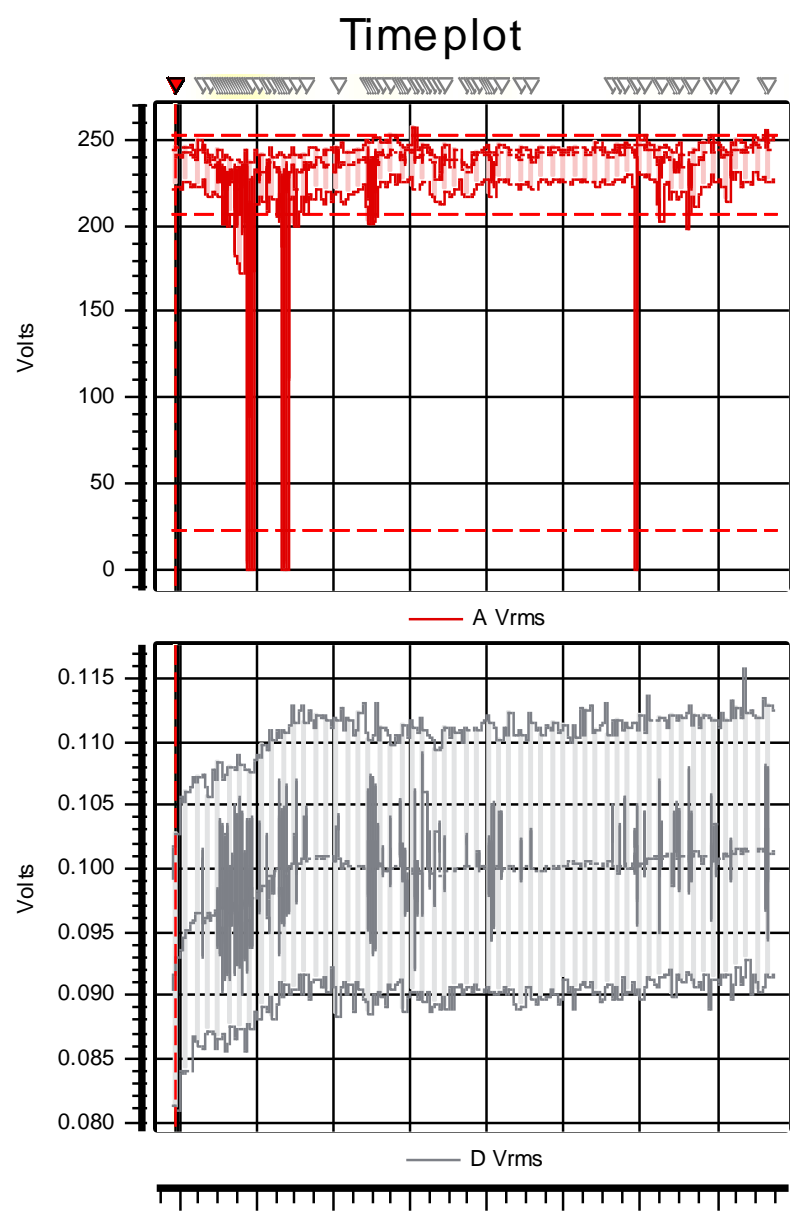

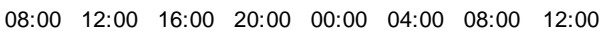

Fig. 6 Time plot survey of a POS of a residence

The ITIC curve reveals nineteen points (the green dots) in which the rms voltage is below the tolerance curve and one above the tolerance curve (Fig. 7).

The statistics of the relevant events according with the standard EN 50160 is delivered by the power analyzer in Table 1 and in the histogram presented in Fig. 8.

In Figs. 9 and 10 are depicted the features of a sample recorded by the analyzer. It is a mild bipolar impulsive transient followed by a dip. Its features are "mutatis mutandis" similar to those depicted in the above section. It may be noted that the voltage rms value drops to $126.44 \mathrm{~V}$, along with a THDV of $37.44 \mathrm{~V}$ and $32.13 \%$ in relation to the fundamental.

As for the standard EN 50160, the survey revealed an uncompleted fail presented in Fig. 11. All the features failed, without the power frequency.
Magnitude/Duration plot

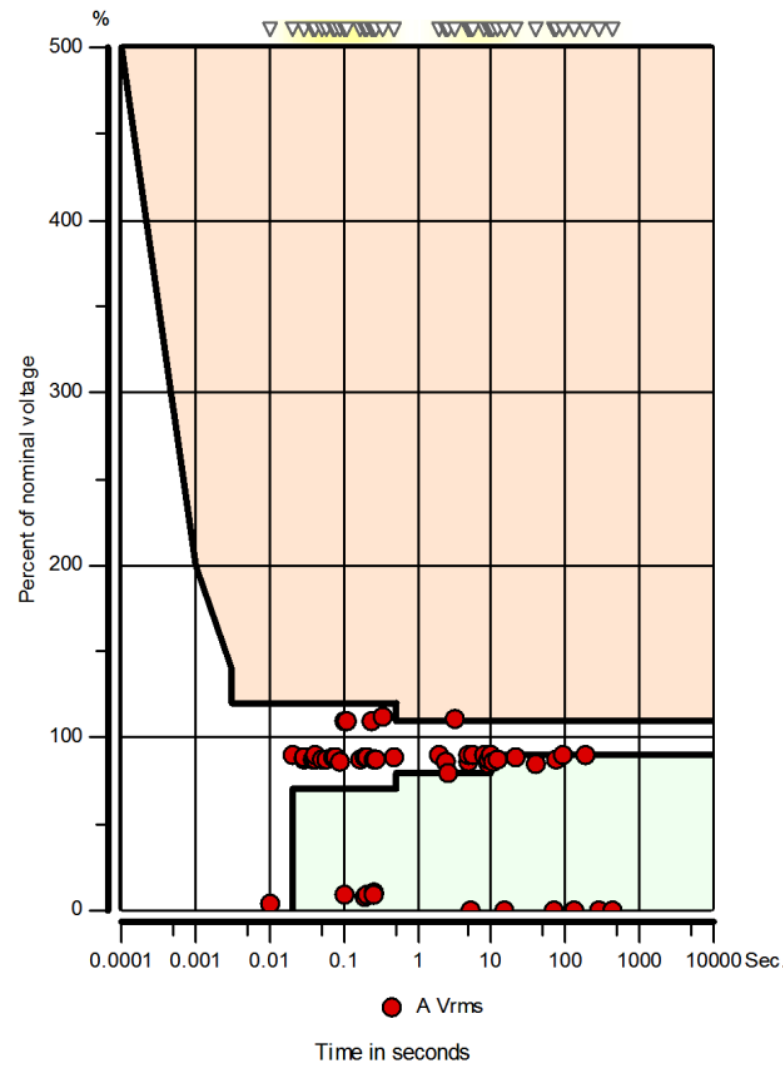

TOLERANCE CURVE: ITIC Nominal voltage $(100 \%)=230 \mathrm{~V}$ Variations ABOVE tolerance curve 1 Variations BELOW tol erance curve 19

Fig. 7 The ITIC curve of the survey

Table 1

\begin{tabular}{|c|c|c|c|c|c|c|c|c|c|}
\hline \multirow{2}{*}{\multicolumn{2}{|c|}{ Depth (\%) }} & \multicolumn{8}{|c|}{ Duration } \\
\hline & & \multirow{2}{*}{$\begin{array}{l}\mathrm{msec} \\
10<100\end{array}$} & \multirow{2}{*}{$\begin{array}{l}\text { Sec. } \\
.1<5\end{array}$} & \multirow{2}{*}{$\begin{array}{l}\text { Sec. } \\
0.5<1\end{array}$} & \multirow{2}{*}{$\begin{array}{l}\text { Sec. } \\
1<3 \\
\end{array}$} & \multirow{2}{*}{$\begin{array}{l}\text { Sec. } \\
3<20\end{array}$} & \multirow{2}{*}{$\begin{array}{l}\text { Sec. } \\
20<60\end{array}$} & \multirow{2}{*}{$\begin{array}{l}\min \\
1<3\end{array}$} & \multirow{2}{*}{$\frac{\min }{>3}$} \\
\hline From & to $<$ & & & & & & & & \\
\hline \multicolumn{10}{|l|}{ Dips } \\
\hline 0 & 10 & 0 & 0 & 0 & 0 & 0 & 0 & 0 & 0 \\
\hline 10 & 15 & 0 & 0 & 0 & 0 & 0 & 0 & 0 & 0 \\
\hline 15 & 30 & 0 & 0 & 0 & 0 & 0 & 0 & 0 & 0 \\
\hline 30 & 60 & 0 & 0 & 0 & 0 & 0 & 0 & 0 & 0 \\
\hline 60 & 99 & 16 & 9 & 0 & 3 & 8 & 2 & 4 & 3 \\
\hline \multicolumn{10}{|c|}{ Interruptions } \\
\hline 99 & 100 & 0 & 0 & 0 & 0 & 0 & 0 & 0 & 0 \\
\hline \multicolumn{10}{|c|}{ Temporary Overvoltages } \\
\hline 110 & 120 & 0 & 1 & 0 & 0 & 0 & 0 & 0 & 0 \\
\hline 120 & 140 & 0 & 0 & 0 & 0 & 0 & 0 & 0 & 0 \\
\hline 140 & 160 & 0 & 0 & 0 & 0 & 0 & 0 & 0 & 0 \\
\hline 160 & 200 & 0 & 0 & 0 & 0 & 0 & 0 & 0 & 0 \\
\hline 200 & & 0 & 0 & 0 & 0 & 0 & 0 & 0 & 0 \\
\hline
\end{tabular}

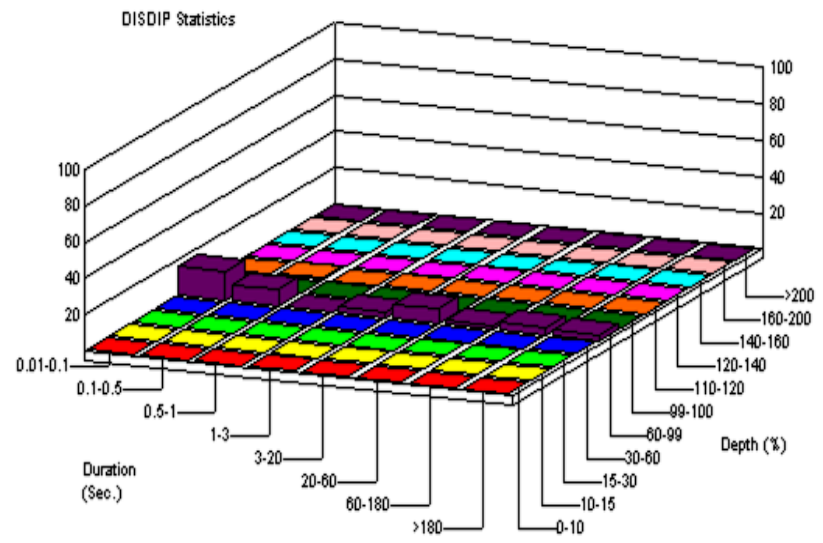

Fig. 8 Histogram of the relevant events 


\section{Event Details/Waveforms}

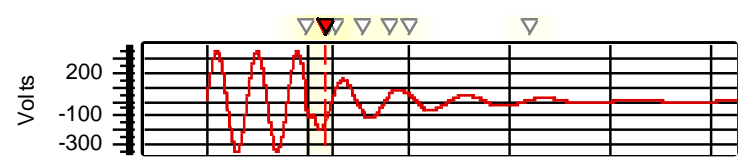

- A V — D V

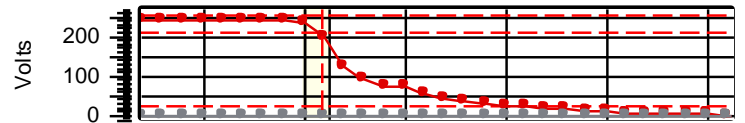

— A Vrms (val) _ D Vrms (val)

\begin{tabular}{ll|l|l|l|} 
07:45:54.95 & $07: 45: 55.05$ & $07: 45: 55.15$ \\
$09 / 06 / 2009$ &
\end{tabular}

Event \#860 at 09/06/2009 07:45:55.000

AV Mild Bipol Trans Neg 1/4 Cyc

CATEGORY: Impulsive Transient (microsec duration)

$\begin{array}{ll}10 \% \text { Ampl } & -118.8 \\ 50 \% \text { Ampl } & -33.64 \\ 90 \% \text { Ampl } & 53.9 \\ 10 \% \text { Offset (usec) } & 9343 \\ 50 \% \text { Offset (usec) } & 11257 \\ \text { Rise time 10-90\% (usec) } & 4004 \\ \text { Worst Peak-to-Peak } & 248.9\end{array}$

Worst Peak-to-Peak 248.9

$\begin{array}{llllllll} & \text { A } & \text { B } & \text { C } & \text { D } & \text { A-B } & \text { B-C } & \text { C-A } \\ \text { Vrms } & 194.9 & 0.08985 & 0.1034 & 0.09571 & 194.9 & 0.1514 & 194.9 \\ \text { VPeak } & 340.6 & 0.2732 & 0.2747 & 0.2739 & & & \end{array}$

Fig. 9 Waveform of a mild bipolar transient

\section{Wav eform harmonics}

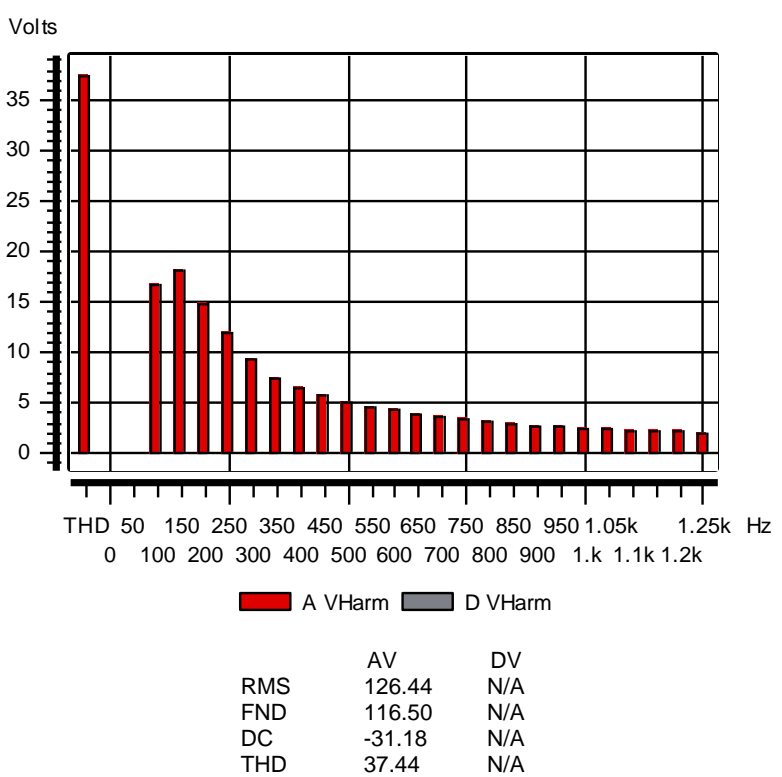

Fig. 10 The discrete frequency spectrum of the event

\section{Conclusions}

The monitoring objective of the survey depicted in the above section was diagnosis and not the investigation of the overall quality of the system. Consequently the requirements of the standard EN 50160 are of minor importance in the present approach.
EN50160 Uncompleted - Fail

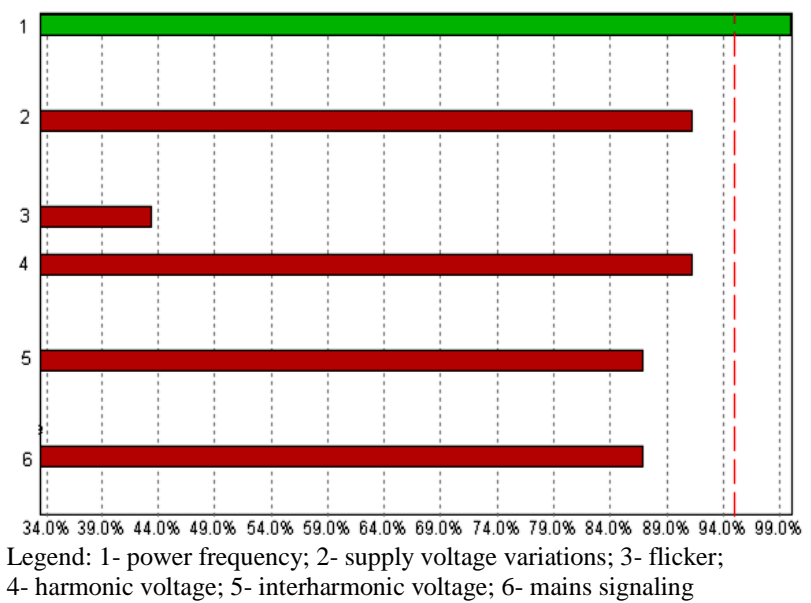

Fig. 11 Results according with the standard EN 50160

It was a reactive mode of power quality survey, determined by the misoperation of the home automation in the residence, which was the first step to a solution.

Speaking about the standard EN 50160 itself, it should be understood as representing a compromise between the three parties which exert an influence on the power quality, i.e. network operator, network user, and manufacturer of equipment. Each of these three parties has an interest in playing their part.

It was obvious that some mitigation measures have to be provided by the user, or a separate agreement for a higher supply quality must be negotiated with the supplier.

\section{References}

[1] IEEE Std. 1159-1995 R2001- IEEE Recommended Practice for Monitoring Electric Power Quality

[2] IEC 61000-4-30 Edition 3.02015 - 02 - Electromagnetic compatibility (EMC) - Part 4-30: Testing and measurement techniques - Power quality measurement methods

[3] IEEE STD 519-2014, Recommended Practice and Requirements for Harmonic Control in Electrical Power Systems

[4] Arrillaga, J., Watson N.R., Power System Harmonic Analysis, John Wiley \& Sons. Inc., 2003

[5] Kusko, A., Thompson, M.T., Power Quality in Electrical Systems, The McGraw-Hill Companies, Inc., 2007

[6] EN 50160:2010+A1:2015, Voltage characteristics of electricity supplied by public electricity networks

[7] Buzdugan, M.I., Bălan, H., Power Quality Issues in Brushless DC Adjustable Speed Drives, International Conference on Renewable Energies and Power Quality, Cordoba, 2014 